\title{
CESPUC
}

\section{A LOUCURA E AS PEDRAS NA LITERATURA DE DRUMMOND}

\section{Cristina Maria Ribeiro de Oliveira*}

\begin{abstract}
Resumo
A sociedade, em várias épocas, segregou a loucura nos espaços sociais como na rua, no internamento, nas prisões ou na própria casa do sujeito. Para Foucault (1978), a loucura foi e continua sendo objeto de um olhar que torna invisível as diferenças, com intolerância e medo. É no espaço e no tempo da cidade que os sujeitos se encontram e se desencontram, desenvolvendo seus vínculos ou os desatando com seus desejos, afetos, conflitos. A loucura pode ser representada na literatura que absorve o imaginário do escritor para enunciar cenas que refletem o cotidiano, abordam a realidade, constroem outra e trazem para o leitor as infinitas possibilidades de resolver as tensões do texto. Este artigo tem como objetivo analisar o conto, de Carlos Drummond de Andrade, "A Doida", que está inserido no livro "Contos de Aprendiz" (1951), trazendo o olhar infantil para a percepção da loucura que se desloca da agressão à louca, quando os meninos atiram pedras contra ela, para a solidariedade e sensibilidade humanas, representadas por um dos meninos, quando ele descobre que a louca é uma velha, uma mulher, que merece ser cuidada no seu leito de morte.
\end{abstract}

Palavras-chave: Doida. Meninos. Medo. Pedra. Velha. Mulher.

\section{THE MADNESS AND THE STONES IN DRUMMOND'S LITERATURE}

Society, in various times, segregated mad people from social spaces such as the street or did it into the hospitalization, into prisons or into their homes. To Foucault (1978), they have been and continue to be considered as an object to belooked at, which makes differences invisible, in the context of in tolerance and fear. It is in the time and the space of the city that people find and lose themselves, developing their attachmentor untangling their desires, emotions, conflicts. Madness can be represented in the literature which absorbs the writer imagination to enunciate scenes that reflect everyday life, deal with reality, construct another one filled with imagination and also bring to the reader infinite possibilities of solving the text tensions. This article focuseson analyzing the short story by Carlos Drummond de Andrade, "The mad woman", which is included in the book "Apprentice Tales" (1951). This analysis brings the child's look to the perception of madness which moves itself from the aggression against the woman, when the boys throw rocks at her, to the solidarity and human sensitivity, represented by one of the boys, when he finds out that the mad woman is an old one, who deserves to be taken care of on her deathbed.

Keywords: Crazy. Boys. Fear. Stone. Old woman.

Recebido em: 09/04/2019

Aceito em: 10/04/2019

* Pontifícia Universidade Católica de Minas Gerais (PUC - Minas). Doutoranda em Literatura de Línguas Portuguesas do programa de Pós Graduação em Letras da PUC-Minas. Professora de Psicologia Centro Universitário UNA. 


\section{CARLOS DRUMMOND E OS CONTOS DE APRENDIZ}

A loucura é um fenômeno causador de segregação desde que substituiu a lepra no cenário das cidades. A nau dos loucos é um exemplo da forma como eles eram tratados: para não andarem sem rumo pela cidade, a nau se tornava uma prisão que levava para longe a loucura, tornando-os seres invisíveis, entregues a seu destino. Segundo Foucault (1978), o homem medieval demonstra a:

situação simbólica e realizada ao mesmo tempo pelo privilégio que se dá ao louco de ser fechado às portas da cidade: sua exclusão deve encerrá-lo; se ele não pode e não deve ter outra prisão que o próprio limiar, seguram-no no lugar de passagem. Ele é colocado no interior do exterior, e inversamente. Postura altamente simbólica e que permanecerá sem dúvida a sua até nossos dias, se admitirmos que aquilo que outrora foi fortaleza visível da ordem tornou-se agora castelo de nossa consciência. (FOUCAULT, 1978, p. 16)

O louco encontra-se, desde essa época, sem um lugar na cidade que possa apresentar sua singularidade ou torna-se objeto de exclusão de uma sociedade que não aceita a desrazão e sim a ordem. A loucura tornou-se, então, objeto também da literatura que, pela ficção, trouxe como tema a segregação social existente no cotidiano das cidades que, ao mesmo tempo, fascina, amedronta e apresenta ao leitor a reflexão sobre a singularidade de cada sujeito e como a sociedade percebe e reage frente ao estranho, às diferenças. Evidencia-se que essa é uma questão social atual, pois as portas continuam fechadas para o louco no mundo moderno, como bem encena a literatura. Mesmo quando as prisões são construídas, o simbolismo de exclusão do sujeito permanece.

A criação literária nutre-se do imaginário, construindo arbitrariamente sujeitos em situações de fantasia, nas quais a subjetividade do escritor se desnuda com todos os seus sentimentos, maneiras de ver o mundo e sua capacidade de julgar as ações humanas, mas encontra-se no eixo da razão:

Enquanto o louco apodera-se das fantasias criadas por sua imaginação e age em consonância com a lógica desse universo irreal que ele crê verdadeiro, o escritor constrói seres e mundos ficcionais, aos quais também se abandona, alienando-se, momentaneamente, da realidade circundante (BARRAL, 2001, p. 14).

Verifica-se que tanto o louco quanto o escritor utilizam do imaginário e constroem outra realidade. A relação entre a literatura e a loucura diz respeito também à linguagem, pois cada uma é conduzida por elementos singulares que enunciam um sentido, utilizando tanto metáforas quanto símbolos e imagens que traduzem verdades. Aplicar a transgressão como forma de demonstrar subjetividade também se relaciona com as duas instâncias, nas quais ajuizar valor não tem sentido, pois a realidade já se decompôs (BARRAL, 2001).

Carlos Drummond de Andrade, ao se abrir para a prosa, nesse tema da loucura, foi um dos autores que retratou e denunciou o banimento do louco do espaço social. A narrativa, de cunho 
autobiográfico, com quinze contos, retrata um movimento geral que vai sempre do interior para a capital, da infância para o mundo adulto, da vida para a morte, em cenas que abordam a vivência no mundo, de crianças com idade de onze a treze anos. O tempo das narrativas se situa em aproximadamente 1920, no espaço da cidade e com um fio condutor que aprofunda o mal, com questões sociais, mentais ou morais em todos os contos (MOURA, 2012, p. 24).

Segundo Antonio Candido (1999), o leitor das primeiras obras de Drummond percebe que as emoções encontram-se contidas, mas nos próximos livros elas se manifestam seja abordando a sua família, seja apresentando o desejo de expressar o social, trazendo a política para o seu mundo poético.

Este texto tem como objetivo analisar o conto de Drummond, denominado "A Doida", inserido no livro Contos de Aprendiz, que foi publicado em 1951, período do pós-guerra, que narra a loucura feminina e encena com muita sensibilidade um problema político. Tem como protagonistas três meninos, entre onze e treze anos, e uma louca que reside em uma casa na cidade, que por várias gerações foi atiçada pelos adolescentes:

Os três garotos desceram manhã cedo, para o banho e a pega de passarinho. Só com essa intenção. Mas era bom passar pela casa da doida e provocá-la. As mães diziam o contrário: que era horroroso, poucos pecados seriam maiores. Dos doidos devemos ter piedade, porque eles não gozam dos benefícios com que nós, os sãos, fomos aquinhoados (ANDRADE, 2012, p.24).

Os homens são propensos a atos de mútua agressividade, o que acarreta a permanente ameaça da civilização de se desintegrar e para tanto precisa colocar limites nos instintos de agressão e controlar suas manifestações (FREUD, 1930).

No conto "A Doida", além dos movimentos já citados por Moura (2012), há vários outros como o que vai da rua, onde estão os meninos, em direção à casa da doida, saindo do público para o privado; do menino que passa da infância, fase lúdica, para a vida adulta quando se torna responsável, saindo de uma vida de prazer para a responsabilidade adulta de compreender o sujeito, com suas diferenças. Movimenta-se também no que diz respeito à segregação da doida que se inicia ou no casamento, quando é rejeitada pelo marido, ou quando o pai a expulsa de casa; e continua na rua com os meninos, com atos de expulsão do micro, família, para o macro, cidade. São todos atos realizados pelo poder masculino. A Doida do conto é excluída do convívio com outros sujeitos pela família, que a afasta da sociedade.

No que se refere ao narrador, ele encena o conto na terceira pessoa, de forma distanciada, pois assim "tem uma visão mais ampla dos fatos, uma vez que a instância responsável pela narração não coincide com nenhum personagem, um rememorador do passado e vedor do futuro. É através dele que o ritmo da trama é criado" (VICTORASSO, 2015, p. 38). 


\section{A LOUCURA COMO DIFERENÇA E EXCLUSÃO}

As causas da loucura, no conto, são buscadas no passado, as quais podem ser originárias de uma ruptura entre a doida e as relações com as figuras ou paterna ou do esposo, o que acarretaria uma culpa decorrente do papel feminino que a mulher deveria realizar na sociedade (SILVA, 2017).

A pedra é um significante que se repete nos contos e na poesia de Drummond, que nasceu em Itabira, cidade que traz pedra no nome, cuja origem é a língua Tupi (Ita). Podem-se citar os textos "O Doido", "No meio do Caminho tinha uma pedra" e "A Doida", os quais também trazem impressos esse signo. O poema "No meio do Caminho" (1930) aborda o enigma do caminhar, retratando a impossibilidade de existir uma solução ao problema, ao dizer: "no meio do caminho tinha uma pedra, tinha uma pedra no meio do caminho" (ANDRADE, 2002, p. 16).

No poema "O Doido", do livro Boitempo: esquecer para lembrar (2017), o eu-lírico utiliza a expressão "mas se ele endoida de jogar pedra vai preso no cubículo mais tétrico e doloroso da cadeia" (ANDRADE, 2017, p. 73). Nesse poema, o louco, que passeia calmamente pelas ruas, joga pedra quando a desrazão se instala, sendo ele quem atira as pedras na sociedade.

No conto "A Doida", a pedra vai se deslocando no texto: o narrador encena pedras soltas ao se referir ao espaço da rua, deixando pistas de onde se buscam as pedras que serão atiradas; depois ela é jogada pelos meninos, da rua contra a casa, onde se encontra a doida, sendo um objeto que representa o mal, a agressividade humana; em outro momento, o menino abre a cancela, fica em frente ao chalé, com a pedra na mão e sente que ela é desnecessária e a joga fora; quando ele fica frente a frente com a doida, dentro da casa, ela cobre os olhos com a mão como para protegê-los da pedrada. A pedra é uma metáfora que simboliza a forma como a sociedade trata a louca: as crianças, por várias gerações, jogam pedras literalmente na sua casa; o pai a expulsou de casa; o marido a abandonou; a família não mantém relações com ela; mas a pedra também pode se transformar em vínculo, em laços como no final do conto, com o menino que segurou sua mão quando ela estava morrendo ou com os primos que lhe enviam comida e roupas. A pedra é, portanto, uma metáfora da segregação social que empurra para longe o seu objeto de exclusão que é a loucura:

O sentimento de que a doida carregava uma culpa, que sua própria doidice era uma falta grave, uma coisa aberrante, instalou-se no espírito das crianças. E assim, gerações sucessivas de moleques passavam pela porta, fixavam cuidadosamente a vidraça e lascavam uma pedra. Aprincípio, como justa penalidade. Depois, por prazer. Finalmente, e já havia muito tempo, por hábito. Como a doida respondesse sempre furiosa, criara-se na mente infantil a idéia de um equilíbrio por compensação, que afogava o remorso (ANDRADE, 2012, p.25).

Nesse conto, quem provoca a ira é a sociedade que acredita na existência de uma culpa e que, portanto, era necessário ter uma pena para purgar a falta grave, o pecado que a louca cometeu. O jogar pedra é uma metáfora que significa expulsar e elas foram jogadas por muitos. 
Antes de ser doida, há uma rejeição do pai e/ou do marido: um que a expulsa de casa e outro que a abandona, havendo sempre um desatar de nós que denotam a falta de vínculo. A doida estava só. Com a quebra de todos os seus laços sociais anteriores à perda da razão, a loucura se instala quando ela ocupa o chalé e a partir de então a doida se isola: "Repudiada por todos, ela se fechou naquele chalé do caminho do córrego, e acabou perdendo o juízo. Perdera antes todas as relações. Ninguém tinha ânimo de visitá-la. O padeiro mal jogava o pão na caixa de madeira, à entrada, e eclipsava-se" (ANDRADE, 2012, p. 23).

O narrador, de terceira pessoa, enfatiza que a doida, anteriormente aos processos de abandono e de rejeição era uma moça como as outras. Ele sinaliza que a falta de afeto pode levar à loucura, que as relações sociais são fundamentais para a constituição do sujeito e sua inserção na sociedade. Esse abandono é evidenciado tanto ao apontar as mazelas no entorno do chalé quanto ao cenário de guerra montado para a fuga, em momentos que a louca vivenciava quando recebia pedradas por longos quarenta anos: "Passou a outra janela e viu o mesmo abandono, a mesma nudez. Mas aquele quarto dava para outro cômodo, com a porta cerrada. Atrás da porta devia estar a doida, que inexplicavelmente não se mexia, para enfrentar o inimigo" (ANDRADE, 2012, p. 23).

Pode-se fazer uma analogia com o suplício realizado e citado por Foucault (1977), quando relata cenas de como, antes das prisões, os transgressores eram penalizados no que se assemelha com as cenas do conto e em forma de espetáculo, como os meninos faziam com a doida. Há um prazer ao perceber o sofrimento do diferente, do excluído com a preponderância do mal em um ritual de poder. Há um processo de tornar invisível o sujeito acometido de loucura com uma punição física, no caso o jogar pedra, que também é uma expressão que no cotidiano significa ficar louco. Nesse conto, quem joga pedra são os meninos e não a louca. Há uma inversão de sentido para que a loucura surja. O jogar pedra dos meninos é também uma forma de isolar a doida dos laços sociais, de estabelecer vínculos ou de formar laços pela agressividade e pela ira:

Se a loucura conduz todos a um estado de cegueira onde todos se perdem, o louco, pelo contrário, lembra a cada um sua verdade; na comédia em que todos enganam aos outros e iludem a si próprios, ele é a comédia em segundo grau, o engano do engano. Ele pronuncia em sua linguagem de parvo, que não se parece com a da razão, as palavras racionais que fazem a comédia desatar no cômico: ele diz o amor para os enamorados, a verdade da vida aos jovens, a medíocre realidade das coisas para os orgulhosos, os insolentes e os mentirosos (FOUCAULT, 1978, p.19).

\section{A MORTE E A SOLIDARIEDADE}

Para Freud (1930), o sofrimento humano provém do corpo, do mundo externo ou das relações sociais o que coloca o sujeito pressionado e realizando atos que diminuem a perspectiva de obter felicidade e de usufruir do princípio do prazer. Para evitar o sofrimento proveniente das relações interpessoais, o sujeito pode utilizar, como mecanismo de defesa, o distanciar-se das outras pessoas, se isolando. Também o sujeito pode considerar a realidade como causadora de seu sofrimento e para ser feliz rompe com todas as suas relações sociais. É o que faz o louco 


\section{CESPUC \\ 1 O SEMESTRE DE $2019-$ N. 34}

\section{(ristina mabia Ribeiro de Ouiveira}

ao recriar a realidade, eliminando o insuportável e procurando substitutos para o seu desejo:

Pessoas sensíveis lamentavam o fato, sugeriam que se desse um jeito para internar a doida. Mas como? O hospício era longe, os parentes não se interessavam. E daí - explicava-se ao forasteiro que porventura estranhasse a situação - toda cidade tem seus doidos; quase que toda família os tem. Quando se tornam ferozes, são trancados no sótão; fora disto, circulam pacificamente pelas ruas, se querem fazê-lo, ou não, se preferem ficar (ANDRADE, 2012, p. 23).

No que se refere ao feminino, há um deslocamento na forma, nos significantes. Se no início havia a doida, objeto de violência física, quando o menino se encontra com ela dentro do chalé, os afetos vão brotando e a doida vai se tornando, aos poucos, uma velha e de forma carinhosa o menino sinaliza que ela era pequenininha, até ser uma mulher que necessita de amor, de solidariedade, quando se encontra à beira da morte. Há uma inversão na posição dos dois: o menino se torna um adulto que cuida, acolhe a doida que agora é uma mulher:

Foi tropeçando nos móveis, arrastou com esforço o pesado armário da janela, desembaraçou a cortina, e a luz invadiu o depósito onde a mulher morria. Com o ar fino veio uma decisão. Não deixaria a mulher para chamar ninguém. Sabia que não poderia fazer nada para ajudá-la, a não ser sentar-se à beira da cama, pegar-lhe nas mãos e esperar o que ia acontecer (ANDRADE, 2012, p. 28).

A doida do conto é excluída do convívio com outros sujeitos a partir da família para a sociedade, o que denota, para a recepção da obra, que se a loucura não for aceita por cada um, seremos todos prisioneiros da segregação do diferente. $\mathrm{O}$ medo aparece explicitamente tanto pela velha, que tem medo de levar uma pedrada, quanto pelo menino que tem medo que a velha receba uma pedrada que vem da rua:

Seria caso talvez de chamar alguém, avisar o farmacêutico mais próximo, ou ir à procura do médico, que morava longe. Mas hesitava em deixar a mulher sozinha na casa aberta e exposta a pedradas. E tinha medo de que ela morresse em completo abandono, como ninguém no mundo deve morrer, e isso ele sabia que não apenas porque sua mãe o repetisse sempre, senão também porque muitas vezes, acordando no escuro, ficara gelado por não sentir o calor do corpo do irmão e seu bafo protetor (ANDRADE, 2012, p.27).

A doida, na cidade, permite que cada um mostre a sua face do mal: seja jogando pedras, seja virando as costas, expulsando um sujeito de casa ou o abandonando. Essa segregação é apontada em cada ato dos personagens que se relacionam com a doida cuja loucura assume o lugar da verdade e mostra a cada um a sua verdade, os seus conflitos. 


\section{REFERÊNCIAS}

ANDRADE, Carlos Drummond de. Poesia Completa. Rio de Janeiro: Nova Aguilar, 2002.

ANDRADE, Carlos Drummond de. Contos de aprendiz. $1^{\text {a }}$ ed. São Paulo: Companhia das Letras, 2012.

ANDRADE, Carlos Drummond de. Boitempo: Esquecer para lembrar. São Paulo: Companhia das Letras, 2017.

BARRAL, Gislene. Vozes da loucura, ecos na literatura. Revista Estudos de Literatura Brasileira Contemporânea, $n^{\circ}$ 12. Brasília, março/abril de 2001, p. 13- 38.

CANDIDO, Antonio. Iniciação à Literatura Brasileira. 3. ed. São Paulo: Humanitas Publicações FLCH/USP, 1999.

FREUD, Sigmund. O Mal estar e a Cultura. Rio de Janeiro: Editora Imago, 1930.

FOUCAULT, Michel. A História da Loucura. Editora Perspectiva: São Paulo. 1978.

FOUCAULT, Michel. Vigiar e punir: história da violência nas prisões. Petrópolis: Vozes, 1977.

MOURA, Murilo Marcondes de. Caderno de leituras Carlos Drummond de Andrade. Companhia das Letras. 2012

SILVA, Roniê Rodrigues da. Representações da Loucura na Obra de Carlos Drummond de Andrade. Revista Araticum, Programa de Pós-graduação em Letras/Estudos Literários da Unimontes, v.16, n.2, 2017.

VICTORASSO, Renata Bombonato. Literatura e Psicanálise: a loucura em contos de Drummond e Allan Poe. Revista Letras Fafibe, São Paulo, v. 5 (1), 2015. 